\title{
The Rate of Emotional Divorce and Predictive Factors in Nursing Staff in North of Iran
}

\author{
Mohammad Hassan Sahebihagh', Zahra Khorshidi2 ${ }^{*}$, Shirin Barzanjeh Atri ${ }^{3}$, Mohammad Asghari \\ Jafarabadi ${ }^{4}$, Afagh Hassanzadeh Rad ${ }^{5}$
}

\begin{abstract}
Objectives: One stage of divorce is emotional divorce, in which, couples live separately under the same roof. This situation seems to happen for most nurses, due to the job conditions, working long hours, stressful job and low salary, as well as the impact of workplace stress on marital relations. This article was intended to assess the rate of emotional divorce among nurses who worked in hospitals of Rasht, Iran.

Materials and Methods: This was a descriptive cross-sectional study, for which 382 nurses from hospitals of Rasht were selected by the way of quota and random sampling. The desired survey consisted of a 2-part questionnaire: demographic information, and Gottmann's emotional divorce scale. Results were analyzed using SPSS software (version 19.0), and t test, analysis of variance (ANOVA), and logistic regression were used. $P<0.05$ and $\mathrm{CI}=95 \%$ were considered significant.

Results: The results showed that the participation rates for women and men were $93.5 \%$ and $6.5 \%$, respectively. Moreover, the rate of emotional divorce among nurses who participated in this study was 7.6\%. The main predictive variables for emotional divorce were living with spouse's family, having relationship with family members, and attempt to divorce.

Conclusions: Although the results suggested low rate of emotional divorce among nurses who lived in Rasht, it is recommended that appropriate ways be used for improving a life of greatness and emotional support of couples, and also improving the nurses' quality services for calmness in married life, to decrease this low percentage with regard to the importance of this subject.

Keywords: Divorce, Emotional divorce, Iran, Nurses
\end{abstract}

\section{Introduction}

Matrimony is started with man and woman marriage, this means that they formed the family $(1,2)$. Marriage is in against of the divorce (3). One of the important issues in Islam is family establishment (4). Amato suggests that the divorce is the saddest problem within the 20th century (5). The divorce rate has been increased from 50-60 years ago up to now, so that today $50 \%$ of marriages in Norway and the United States end in divorce or separation $(6,7)$. In Sweden, the marriage rate has been decreased from $90 \%$ to $75 \%$ during 1970-2010 (8). The separation rate of Italian couples have been reported 70\% during 1995-2010 (9). In Australia, 20\% of marriages ends in divorce (7). Raymo and colleagues reported that divorce rates in Japan has grown increasingly from $12 \%$ in 1980 to $17 \%$ in 1990 (10). Unfortunately, the divorce rates also has unexpectedly increased in Iran (11), so that the divorce rate in 2011 (45\%) has been increased in comparison with its rate in 2006, and 153 divorces have occurred per 1000 marriages (4). The official statistics of National Organization for Civil Registration (NOCR) indicates an increase of divorce rate, and 83277 records of divorce within 6 months in 2015 .
It also showed that the ratio of marriage to divorce was $4.4 \%$ which means 1 in 4 marriages ended in divorce. The city of Rasht (center of Guilan province, Iran) is ranked as the fifth city among other Iranian provinces (12), although the official statistics show that the divorce rate decreased by increasing the marriage age. Most of the divorces substantially occurred among the couples whose marriage age were more than 20 (12). There are 2 types of divorce: absolute divorce and limited divorce; in the first type family collapses, and in the second type there is a hidden situation of divorce, so that the couples due to the necessity and coercion live together under the same roof without any good and suitable relationship (13).

The process of divorce is not sudden and it happens very slowly over the time. American couples who cannot come to an agreement for continuing their matrimony, live apart for a short time in order to assess their marriage before making a decision for getting official divorce (14). In fact, separation is an awareness condition and part of a divorce process (14). But in the countries with traditional structures, such as Iran where the rate of divorce is lower and the amount of emotional separation (emotional

Received 20 September 2016, Accepted 7 May 2017, Available online 3 June 2017

${ }^{1}$ Tabriz Health Services Management Research Center, Community Health Nursing Department, Tabriz University of Medical Sciences, Tabriz, Iran. ${ }^{2}$ Community Health Nursing Department, Tabriz University of Medical Sciences, Tabriz, Iran. ${ }^{3}$ Community Health Nursing Department, Faculty of Nursing and Midwifery, Tabriz University of Medical Sciences, Tabriz, Iran. ${ }^{4}$ Road Traffic Injury Research Center, Tabriz University of Medical Sciences, Tabriz, Iran. ${ }^{5}$ Pediatrics Growth Disorders Research Center, 17th Shahrivar Hospital, Guilan University of Medical Sciences, Guilan, Iran. *Corresponding Author: Zahra Khorshidi, Tel: 09111489616, Email: khorshidiza@gmail.com 
divorce) are high (15), short time separation may result in decrease of couples' reliance and continuity of life (16). Couples, especially women, accept this cold life because of several reasons such as: lack of economic independence, children, and social traditions (17). Couples who experience emotional divorce are lone people who get involved in dissatisfied marriage (18). Colman et al showed that the people who have experienced emotional divorce or separation, have been referred to the psychologist more than married people (19). Job stress and job problems affect marital satisfaction. Nursing is one of the 40 stressful jobs (20), and it unconsciously affects the marital life (21). Gottman quoted from Bloom and colleagues that depression, increased traffic collisions, violence and suicide are the consequences of separation and divorce (22). One study on nurses in India by Abdul Azeez showed that mental problems can be caused due to the existence of dissatisfactory conditions between the couples (21). In Iran, Mohsenzadeh et al noted the negative consequences of social, psychological, physical, and economic situations which resulted from marital conflict and divorce. The results of this study also showed that conflicts between spouses, violence, addiction, financial problems and not being self-reliant were the main factors of lack of marital satisfaction and divorce (17). Kitson's book, named "Portrait of Divorce", mentioned that having problem with husband's family, lack of communication, sexual problems and work pressure are the identified factors of divorce (23). There are a few studies about this issue in Iran. In this study, we intended to investigate the emotional divorce and determine the predictive factors which resulted in divorce among nursing society of Rasht, Iran.

\section{Materials and Methods}

This was a descriptive cross-sectional study which was conducted among nurses of medical centers in Rasht. Initial sample size was estimated by using Cochran formula and it was at a significance level of $0.05(P<0.05)$, and then the sample size was increased to 400 due to the likely loss of some samples.

Cross-sectional method was used for selecting 400 samples among a total number of 636 members.

Then, the number of participants in each center was determined. For selecting participants from each medical center, first participant was selected through simple random sampling and subsequent regular random sampling was performed to choose next members. Inclusion criteria were: the couples who lived under the same roof, having at least one child older than 2 years, minimum marriage period of 5 years, and lack of mental disorders according to the participants' responses to this study. Moreover, death of a spouse, divorced, having children younger than 2 years were the exclusion criteria.

A standard questionnaire of emotional divorce was used for collecting the data. Emotional Divorce Scale (EDS) questionnaire is a 24 -item scale that is designed to measure emotional divorce. The first paragraph of questionnaire consisted of demographic characteristics of the subjects. This paragraph included some questions which were about age, education level, spouse's age, spouse's education level, marriage duration, child's age, number of children, spouse's job, history of family marriage, and the economic satisfaction. Paragraphs 2-6 were related to the relationship between individual and her/his family members, relationship with spouse's family, current marital satisfaction, total marital satisfaction, acting for separation from his/her spouse, and the type of the action. Those questions could be answered as 'Good or Normal', 'Average', and 'Poor'.

The next paragraph, indeed, the main part of the questionnaire, included 24 questions that could be answered as 'Yes' or 'No'. The method of calculating rates after collecting responses by 'Yes' was such that if the number of 'Yes' was 8 or more, person suffered from emotional divorce. The quality of questionnaire was certified by Mami and Asghari in Iran (24). The reliability of this survey was evaluated using Cornbrash a by 0.91 and the reliability was excellently confirmed.

Sampling permission was achieved from Ethics Committee of Guilan University of Medical Sciences. All 382 questionnaires were completed within 2 months from July to September 2015.

SPSS software (version 19.0) was used for data analysis and conducting descriptive statistics (i.e., frequency, percentage, mean and standard deviation). Additionally, independent $t$ test and analysis of variance (ANOVA) were used to compare the means. In order to determine the predictive variables of emotional divorce, logistic regression was used.

\section{Results}

The mean age of participants was $39 \pm 7$ years, so most of them $(34.6 \%)$ were in the age range of 36-42. Majority of the participants were women (93.5\%) and $73 \%$ of participants had salaries above 20000000 Rials per month. The results showed that the average ages of spouses of the participants were $41 \pm 6.99$, majorly under 38 years of age (38.1\%).

The mean duration of marriage of studied people was $12 \pm 6.42$, most of which (41.1\%) were in the age group of 5-10 years. The age of children in most cases were between 7 and 14 years (37\%). Moreover, $97.1 \%$ of the study population and $56.1 \%$ of their spouses had a bachelor's degree. And $72.5 \%$ of the participants' spouses were employees. The amount of family marriage was $13.4 \%$ and the results showed that $4.2 \%$ of the couples had lived with her/his spouse family for a while. Furthermore, $60.9 \%$ of participants demonstrated that their economic situation was satisfactory (Table 1).

None of the participants had poor relationship with their own family or his/her spouse's family, so good and average relationships were compared together.

There was a meaningful relationship between 
Sahebihagh et al

Table 1. Distribution of the Relationship Between Demographic Characteristics and Emotional Divorce

\begin{tabular}{|c|c|c|c|c|c|c|c|}
\hline & Variable Level & OR & Lower & Upper & P Value & No. & Percent \\
\hline \multirow{2}{*}{ Gender } & Female & 0.85 & 0.19 & 3.85 & 0.84 & 346 & 93.5 \\
\hline & Male & 0.91 & & & 0.01 & 24 & 6.5 \\
\hline \multirow{2}{*}{ Income } & >20 million Rials & 0.75 & 0.26 & 2.09 & 0.58 & 51 & 26.3 \\
\hline & $<20$ million Rials & 0.13 & & & 0.00 & 143 & 73.7 \\
\hline \multirow{3}{*}{ Age(y) } & $<35$ & 1.04 & 0.38 & 2.79 & 0.93 & 129 & 34 \\
\hline & $36-42$ & 1.39 & 0.55 & 3.55 & 0.48 & 131 & 34.6 \\
\hline & $\geq 43$ & 0.07 & & & 0.00 & 119 & 31.4 \\
\hline \multirow{3}{*}{ Spouse's Age } & $<38$ & 0.97 & 0.37 & 2.56 & 0.96 & 142 & 38.1 \\
\hline & $39-45$ & 1.29 & 0.50 & 3.35 & 1.29 & 120 & 32.2 \\
\hline & $\geq 46$ & 0.07 & & & 0.07 & 111 & 29.8 \\
\hline \multirow{3}{*}{ Marriage duration } & $<10$ & 0.99 & 0.38 & 2.56 & 0.99 & 157 & 41.1 \\
\hline & $11-16$ & 0.58 & 0.49 & 3.45 & 0.58 & 111 & 29.1 \\
\hline & $\geq 17$ & 0.00 & & & 0.00 & 114 & 29.8 \\
\hline \multirow{3}{*}{ Child age } & $2-6$ & 0.69 & 0.27 & 1.74 & 0.43 & 128 & 33.6 \\
\hline & $7-14$ & 0.12 & 0.25 & 1.56 & 0.31 & 141 & 37 \\
\hline & $\geq 15$ & 0.10 & & & 0.00 & 112 & 29.4 \\
\hline \multirow{2}{*}{$\begin{array}{l}\text { Individual's } \\
\text { Education level }\end{array}$} & Above Bachelor & & & & \multirow{2}{*}{0.99} & 370 & 97.1 \\
\hline & Bachelor & & & & & 11 & 2.9 \\
\hline \multirow{4}{*}{ Spouse's education level } & Diploma & 9.00 & 1.84 & 43.91 & 0.07 & 44 & 12.3 \\
\hline & Post diploma & 2.76 & 0.44 & 17.26 & 0.27 & 41 & 11.5 \\
\hline & Bachelor & 2.82 & 0.62 & 12.66 & 0.17 & 201 & 56.1 \\
\hline & Above & 0.02 & & & 0.00 & 72 & 20.1 \\
\hline \multirow{3}{*}{ Spouse's Occupation } & Self employed & 1.24 & 0.54 & 2.82 & 0.60 & 99 & 27 \\
\hline & Employed & 0.08 & & & 0.00 & 266 & 72.5 \\
\hline & Others & & & & & 2 & 0.5 \\
\hline \multirow{2}{*}{ Cousin Marriage } & Yes & 1.04 & 0.34 & 3.13 & 0.94 & 49 & 13.4 \\
\hline & No & 0.08 & & & 0.00 & 318 & 86.6 \\
\hline \multirow{2}{*}{ Living with spouse's Family } & Yes & 3.28 & 0.8 & 12.42 & 0.8 & 15 & 4.2 \\
\hline & No & 0.07 & & & 0.00 & 339 & 95.8 \\
\hline \multirow{3}{*}{ Number of children } & 1 & 1.12 & 0.13 & 9.10 & 0.91 & 215 & 56.3 \\
\hline & 2 & 1.41 & 0.17 & 11.56 & 0.74 & 151 & 39.5 \\
\hline & $\geq 3$ & 0.06 & & & 0.009 & 16 & 4.2 \\
\hline \multirow{2}{*}{ Economic satisfaction } & Yes & 0.71 & 0.31 & 1.60 & 0.41 & 249 & 69.9 \\
\hline & No & 0.10 & & & 0.00 & 107 & 30.1 \\
\hline \multirow{3}{*}{ Relationship With Family } & Good & 0.16 & 0.05 & 0.49 & 0.002 & 291 & 76.4 \\
\hline & Average & 0.41 & & & 0.10 & 82 & 21.5 \\
\hline & Poor & & & & & 1 & 0.3 \\
\hline \multirow{3}{*}{ Relationship with spouse's family } & Good & 0.27 & 0.12 & 0.60 & 0.001 & 305 & 80.1 \\
\hline & Average & 0.18 & & & 0.00 & 72 & 18.9 \\
\hline & Poor & & & & & 8 & 2.1 \\
\hline \multirow{3}{*}{ Current Marriage satisfaction } & Good & 0.07 & 0.03 & 0.18 & 0.00 & 305 & 80.1 \\
\hline & Average & 0.35 & & & 0.00 & 72 & 18.9 \\
\hline & Poor & & & & & 4 & 1 \\
\hline \multirow{3}{*}{ Overall Marriage satisfaction } & Good & 0.07 & 0.03 & 0.17 & 0.00 & 306 & 80.3 \\
\hline & Average & 0.36 & & & 0.00 & 71 & 18.6 \\
\hline & Poor & & & & & 4 & 1 \\
\hline \multirow{2}{*}{ Apply for divorce } & Yes & 6.37 & 1.82 & 22.19 & 0.004 & 13 & 3.4 \\
\hline & No & 0.07 & & & 0.00 & 368 & 96.6 \\
\hline
\end{tabular}

176 | International Journal of Women's Health and Reproduction Sciences, Vol. 6, No. 2, April 2018 
participants and their own family members, so that the good relationship resulted in $84 \%$ less chance of emotional divorce compared with average relationship (odds ratio $[\mathrm{OR}]=0.16$ ); also, the individual's relationship with his/her spouse's family was significant, so that good relationship resulted in $73 \%$ less chance of emotional divorce compared with average relationship $(\mathrm{OR}=0.23)$. The chance of emotional divorce for situations where the marital satisfaction was good, was $92 \%$ less than the average marital satisfaction $(\mathrm{OR}=0.08)$. Moreover, if the marital satisfaction in whole time of the marriage was good, emotional divorce was $93 \%$ less than the average situation $(\mathrm{OR}=0.07)$.

The results showed that $4.3 \%$ of participants attempted to get divorced, and for those whose answers were yes, chance of emotional divorce was 4.6 times higher than people who answered no.

Furthermore, the results indicated that income, age, length of marriage, age of children and education level were not associated with emotional divorce. There was a significant difference between people whose spouses had high school diploma, bachelor, or higher degrees, so that the chance of emotional divorce for diploma group was 9 times higher. Although people with associate degree and bachelor faced emotional divorce 2.8 times more than people with Master's and higher degrees; this finding was not statically significant $(P<0.17)$.

There was no meaningful relationship between emotional divorce and spouse's job. Although the relationship with spouse's family was not significant, its effect was tangible and considerable, so that the chance of emotional divorce for individuals who lived with spouse's family for a short time was 3.3 higher than the couples who had not experienced this situation.

Number of the children and the economic satisfaction were not associated with emotional divorce. Multivariate analysis indicated that variables including living with his /her spouse's family, relationship with her/his family members, and attempt to divorce were the main predictive factors for emotional divorce (Table 1).

The rate of emotional divorce between nurses who participated in this study was reported as $7.6 \%$, among which 353 persons (92.4\%) scored below 8, and 29 of them $(7.6 \%)$ had a score above 8 , indicating less emotional divorce within majority of them.

According to Table 2, the answers "No one does not know me" and "most wanted somebody on my side" had the lowest score (2.9\%) and the highest score (14.9\%) on the basis of emotional divorce, respectively. Furthermore, the mean scores of emotional divorce was $1.88 \pm 3.66$ (Table 2).

\section{Discussion}

The aim of current study was to investigate the rate of emotional divorce occurred among nurses in Rasht, Iran, and suggested that the factors such as living with the spouse's family, person's relationship with family members and history of attempt to divorce, were the main predictive factors of emotional divorce. A study by Najafpoor et al on women who worked in south of Iran showed that the emotional divorce among full-time workers was more than that among women who worked part-time (25). This study was conducted in north of Iran and various cultural issues of north and south of Iran possibly caused the difference. Parvin et al reported the rate of emotional divorce as $6.5 \%$ in Tehran (26) which was consistent with the results of the present study. As the emotional divorce occurs before legal divorce, one of the reasons for low rate of emotional divorce may be the high rate of legal divorce.

Therefore legal divorce happens before the suppression of emotions in couples. Since the number of English articles which investigated the emotional divorce are very rare and their titles were little similar to emotional divorce titles, therefore the results of the current study was compared with the results of some papers which was related to divorce and marital satisfaction. In a study by Gierveld Jde et al conducted on married men and women in the age range of 64 to 92 year old in the Netherlands, the rate of emotional loneliness was reported as $18.4 \%$ for women and $15.8 \%$ for men (27). The reason for this discrepancy was the difference in family structures between Iran and the Netherlands. Furthermore, the statistical society of Gierveld Jde and colleagues' study was old men and women, whereas the statistical society for this study were individuals with an average age of $39 \pm 7$. This paper was consistent with the study of Abdul Azeez "women who work and marital satisfaction". Their result showed that the marital satisfaction among nurses was average (21).

In the present study, there was no significant relationship between income and economic satisfaction with emotional divorce; however, the study of Musai et al (13) in Iran and Raymo et al (10) in Japan showed the opposite results. Perhaps one of the reasons for this difference was that all participants were employed and their income was almost the same. In this study, spouse's education was associated with emotional divorce; the possibility of emotional divorce was low for couples who had higher education. Our results agreed with the results of Musai and collegeues' study in Iran (13), Raymo et al in Japan (10), and Sayer et al in the United States (28). But one American study found that the rate of divorce after separation was higher among women who had higher degrees compared to those with lower degrees (14).

The majority of nurses had the same education level that could explain the lack of significant relationship between the above factor and emotional divorce, but education levels of participants' husbands were different. The present study confirmed the husband's job did not have any significant relationship with emotional divorce which is in agreement with the studies of Sayer et al (28) and Raymo et al in Japan (10). In addition, the study of Raymo 
Table 2. Distribution of Emotional Divorce Rate Among Nurses in Health Centers in Rasht in 2015

\begin{tabular}{|c|c|c|c|c|c|}
\hline & & No. & Percent & No. & Percent \\
\hline 1 & This marriage is much more than what I expected to feel alone. & 356 & 93.2 & 26 & 6.8 \\
\hline 2 & We are not so close together as we wished & 336 & 88.4 & 44 & 11.6 \\
\hline 3 & I feel frivolous in this marriage. & 364 & 95.5 & 17 & 4.5 \\
\hline 4 & Common task is boring to me. & 358 & 94.0 & 23 & 6.0 \\
\hline 5 & Even when we are together, I feel restless and grief. & 364 & 95.3 & 18 & 4.7 \\
\hline 6 & Most of the time I do not know how to entertain myself & 354 & 92.7 & 28 & 7.3 \\
\hline 7 & Occasionally in this marriage, I feel bored and restless. & 326 & 85.6 & 55 & 14.4 \\
\hline 8 & I wish someone feel close to him or his & 367 & 96.1 & 15 & 3.9 \\
\hline 9 & Feeling Loneliness hurts me. & 331 & 86.6 & 51 & 13.4 \\
\hline 10 & I feel there is little in my marriage. & 328 & 85.9 & 54 & 14.1 \\
\hline 11 & I wish more people called me. & 331 & 86.9 & 50 & 13.1 \\
\hline 12 & Often I need someone to be with me. & 325 & 85.1 & 57 & 14.9 \\
\hline 13 & I do not feel being the important part of somebody & 358 & 93.7 & 24 & 6.3 \\
\hline 14 & I do not feel I belong to somebody. & 357 & 93.7 & 24 & 6.3 \\
\hline 15 & I often feel isolated emotionally. & 343 & 90.3 & 37 & 9.7 \\
\hline 16 & In this marriage, I feel abandoned. & 367 & 96.1 & 15 & 3.9 \\
\hline 17 & I do not have someone to rely on. & 359 & 94.2 & 22 & 5.8 \\
\hline 18 & Often I feel I was set asided. & 364 & 95.5 & 17 & 4.5 \\
\hline 19 & No one is familiar with me. & 371 & 97.1 & 11 & 2.9 \\
\hline 20 & Noone perceives me. & 357 & 93.7 & 24 & 6.3 \\
\hline 21 & Often I do not have any fellow. & 357 & 93.5 & 25 & 6.5 \\
\hline 22 & Most time I need someone to speak. & 340 & 89.0 & 42 & 11.0 \\
\hline 23 & Often I feel I was set asided in this marriage. & 362 & 95.5 & 17 & 4.5 \\
\hline 24 & I feel apart. & 363 & 95.3 & 18 & 4.7 \\
\hline
\end{tabular}

et al which was conducted in Japan showed that the rate of divorce in women whose husbands had constant and regular working was half of the women whose husbands did not have a consistent job (10). According to this study, all participants were working with an academic education level and one of the reasons for lack of significant association between these variables was the economic independence of participants which were majorly women $(29,30)$. Furthermore, the duration of marriage had no effect on the emotional divorce in this study.

Study by Gheshlaghi et al (30) in Iran and Sayer et al (28) in the United States showed that increased duration of marriage resulted in reduced rate of divorce. In fact, decrease of divorce rate may partly reflect the increase of emotional divorce. NOCR statistics showed that the probability of divorce was increased after 25 years of marriage, which indicated that there was a positive relationship between duration of the marriage and increasing the possibility of emotional divorce (12). Moreover, there was a negative significant relationship between the number of children and divorce rate according to the study of Gheshlaghi et al (30).

In contrast, the number of children was not significantly associated with emotional divorce in this study, because one of the reasons for continuing the cold life was presence of kids.

Another predictive factors for emotional divorce was individual's connections with their own family and spouse's family.

The study of Colman et al showed that widow and widower who had social supports referred to psychologist less than others without such supports (19). This issue reflects that couples who have a good relationship with families make long friendship between them and therefor the possibility of emotional divorce and divorce is reduced. The possibility of emotional divorce decreases in people who have a good relationship with their own family and spouse's family. Research by Mohsenzadeh et al in Iran showed that one of the causes of conflict between the couples and the provision for divorce is an inappropriate relationship with the spouse's family (17).

This result indicates that the inappropriate relationship of one of the spouses with another spouse's family provides the provision for emotional divorce. The probability of emotional divorce of people who wanted to divorce was lower than those who had no action. Several other studies in America confirm these results (28).

The limitations of this study can be lots of questionnaires, crowded wards, busy nurses, and also nurses' noninclination to offer their private information which caused some nurses to refuse to participate in the study.

\section{Conclusions}

Although the results suggested low rate of emotional divorce 
among nurses who lived in Rasht, it is recommended that appropriate ways be used for improving the life of greatness and emotional support from each couple, and also improving the nurses' quality services for calmness of married life, to decrease this low percentage with regard to the importance of this subject.

\section{Suggestions}

With regard to few studies on the emotional divorce and its effect on family and the role of family members in anticipating and avoiding divorce, following procedure is recommended:

1. Training young couples before marriage, especially in terms of relationship with spouse's family. 2. Conducting more and similar studies on other groups of society, including teachers and housewives.

\section{Conflict of Interests}

None.

\section{Ethical Issues}

The study was approved by Ethics Committee of Tabriz University of Medical Sciences with ethical code: 2015-46. Sampling permission was taken from Guilan University of Medical Science.

\section{Financial Support}

This study was financially supported by Tabriz University of Medical Sciences.

\section{Acknowledgments}

The authors are grateful to Tabriz University of Medical Sciences, Vice chancellery of Research and Technology, that approved the proposal and financial support, and Guilan University of Medical Sciences. We also express our heartfelt thanks to nurses in educational-medical centers in the city of Rasht who participated in this project as well as managers of nursing services.

\section{References}

1. Martin Garcia A. Divorce and Abuse in 16th, 17th and 18th Century Spain. Procedia Social Behav Sci. 2014;161:184194. doi:10.1016/j.sbspro.2014.12.042

2. Hamidian S, Mousavi FS. Emotional intelligence and the mediated role of Self-effectiveness described by marriage satisfaction model. Bull Georg Natl Acad Sci. 2015;9(1):299305.

3. Tebes JM. Contextual Factors and Environmental Differences Between Couples Divorce Compromised and not Compromise. Aula Orientalis. 2015;1:7-10.

4. Aghajanian A, Thompson V. Recent Divorce Trend in Iran. J Divorce Remarriage. 2013;54(2):112-125. doi:10.1080/105 02556.2012.752687

5. Amato PR. The Consequences of Divorce for Adults and Children. J Marriage Fam. 2000;62(4):1269-1287.

6. Reiter SF, Hjorleifsson S, Breidablik HJ, Meland E. Impact of divorce and loss of parental contact on health complaints among adolescents. J Public Health (Oxf). 2013;35(2):278-
285. doi:10.1093/pubmed/fds101

7. Bollen KNL, Verbeke AL, Euwema MC. Computers work for women: Gender differences in e-supported divorce mediation. Comput Human Behav. 2014;30:230-237. doi:10.1016/j.chb.2013.09.006

8. Hatemi PK, McDermott R, Eaves L. Genetic and Environmental Contributions to Relationships and Divorce Attitudes. Pers Individ Dif. 2015;72:135-140. doi:10.1016/j. paid.2014.08.032

9. Rosnati R, Barni D, Uglia D. Adolescents and Parental Separation or Divorce: The Protective Role of Values against Transgressive Behavior. Procedia Social Behav Sci. 2014;140:186-191. doi: 10.1016/j.sbspro.2014.04.407

10. Raymo JM, Fukuda S, Iwasawa M. Educational Differences in Divorce in Japan. Demogr Res. 2013;28(6):177-206. doi:10.4054/DemRes.2013.28.6

11. Shakerian A, Nazari AM, Masoomi M, Ebrahimi P, Danai S. Inspecting the Relationship between Sexual Satisfaction and Marital Problems of Divorce-asking Women in Sanandaj City Family Courts. Procedia Social Behav Sci. 2014;114:327-333. doi:10.1016/j.sbspro.2013.12.706

12. National Organization for Civil registration website. http:// www.sabteahval.ir/. Accessed December 25, 2015.

13. Musai M, Tavasoli G, Mehrara M. The relationship between divorce and economic-social variables in Iran. British Journal Arts Social Sciences. 2011;1(2):89-93.

14. Tumin D, Han S, Qian Z. Estimates and Meanings of Marital Separation. J Marriage Fam. 2015;77(1):312-322. doi:10.1111/jomf.12149

15. Stack S, Gundlach JH. Divorce and sex. Arch Sex Behav. 1992;21(4):359-367.

16. Torvik FA, Gustavson K, Roysamb E, Tambs K. Health, health behaviors, and health dissimilarities predict divorce: results from the HUNT study. BMC Psychol. 2015;3(1):13. doi:10.1186/s40359-015-0072-5

17. Mohsenzadeh F, Nazari AM. Marriage breakup reasons of divorced applicant Couples. International Journal Education Appied Sciences. 2014;1(1):14-25.

18. Stack S. Marriage, Family and Loneliness: A CrossNational Study. Sociol Perspect. 1998;41(2):415-432. doi:10.2307/1389484

19. Colman E, Symoens S, Bracke P. Professional health care use and subjective unmet need for social or emotional problems: a cross-sectional survey of the married and divorced population of Flanders. BMC Health Serv Res. 2012;12:420. doi:10.1186/1472-6963-12-420

20. Peiman PF, Mansour L, Sadeghi M, Purebraham T. The relationship of job stress with marital satisfaction and mental health in nurses of Tehran hospitals. Quartery Journal Career Organizational Counseling. 2013;4(13):2754.

21. Abdul Azeez EP. Employed Women and Marital Satisfaction: A Study among Female Nurses. International Journal Management Social Sciences Research. 2013;2(11):17-22.

22. Gottman JM. A theory of marital dissolution and stability. J Fam Psychol. 1993;7(1):57-75. doi:10.1037/08933200.7.1.57

23. Kitson GC, Holmes WM. Portrait of Divorce: Adjustment to Marital Breakdown. New York: Guilford Press; 1992.

24. Mami S, Asgari M. Their Differentiation and the Role of Attachment Styles in Predicting Emotional Divorce. 
Pathology Conference phenomenon divorce; Islamic Azad University, Saghez; 2014.

25. Najafpoor E, Bardide M, Kazemi Z. Compare Emotional Divorce and Part-Time Secretary Natural Features among Women Working Full-Time and Housewives Shiraz City. Second National Coference Modern Research Humanities; June 2015.

26. Parvin S, Davoodi M, Mohamadi F. Paper: sociological factors influencing emotional divorce in tehran. Sociocultural Strategy Journal. 2013;2:159-85.

27. Gierveld Jde J, van Groenou MB, Hoogendoorn AW, Smit JH. Quality of marriages in later life and emotional and social loneliness. J Gerontol B Psychol Sci Soc Sci. 2009;64(4):497-506. doi:10.1093/geronb/gbn043

28. Sayer LC, England P, Allison PD, Kangas N. She left, he left: how employment and satisfaction affect women's and men's decisions to leave marriages. Ajs. 2011;116(6):1982-2018.

29. Cohen PN. Recession and Divorce in the United States, 2008-2011. Popul Res Policy Rev. 2014;33(5):615-628. doi:10.1007/s11113-014-9323-Z

30. Gheshlaghi F, Dorvashi G, Aran F, Shafiei F, Najafabadi GM. The study of sexual satisfaction in Iranian women applying for divorce. Int J Fertil Steril. 2014;8(3):281-288.

(c) 2018 The Author (s); This is an open-access article distributed under the terms of the Creative Commons Attribution License (http://creativecommons.org/licenses/by/4.0), which permits unrestricted use, distribution, and reproduction in any medium, provided the original work is properly cited. 